\title{
Palliative Care: A Public Health Priority in Developing Countries
}

\author{
RUTH WEBSTER", JUDITH LACEY and SUSAN QUINE
}

\begin{abstract}
Palliative care is an emerging specialist discipline worldwide with the majority of services located in developed countries. Developing countries, however, have higher incidences of cancer and AIDS and most of these patients would benefit from palliative care. While there is prominent coverage of this issue in the palliative care literature, there is limited coverage in the specialist public health literature, which suggests that the challenges of palliative care may not yet have been generally recognized as a public health priority, particularly in developing countries. The aim of this article is to introduce the topic of "Palliative care in developing countries" into the specialist public health literature to raise awareness and stimulate debate on this issue among public health professionals and health policy makers, thereby potentially facilitating establishment of palliative care services in developing countries.
\end{abstract}

Journal of Public Health Policy (2007) 28, 28-39.

doi:I0.1057/palgrave.jphp.3200097

Keywords: palliative care, developing countries, barriers, opioids

THE SIZE OF THE PROBLEM

We ought to give those who are to leave life, the elderly, the terminally ill, those dying slowly of AIDS and cancer the same care and attention that we give to those who enter life - the newborn (I, p. II99).

Of the 57 million people dying each year (2), approximately 6 million deaths are from cancer and 3 million from HIV/AIDS with the majority occurring in developing countries $(3,4)$. Around twothirds of patients with advanced cancer have pain $(5)$ and patients

\footnotetext{
"Address for Correspondence: The George Institute for International Health, Cardiovascular Division, PO Box M20I, Missenden Road, Camperdown, NSW 2050, Australia. E-mail: rwebster@thegeorgeinstitute.org
} 
with HIV/AIDS suffer similarly if not more $(6,7)$. The incidence of cancer and HIV/AIDS in many developing countries is increasing $(4,8)$, and these figures do not take into account other chronic illnesses like diabetes, heart disease and lung disease, which also cause symptoms that are distressing such as shortness of breath, constipation, diarrhea, nausea as well as psychological distress, depression and anxiety. Including family members, or close companions, providing care and support to those who are dying raises the number of people benefiting from palliative care to a potential roo million a year (and possibly more (9)) (I). The majority of these potential beneficiaries reside in developing countries.

For the majority of people dying in the developing world, cure or disease control in the form of surgery, chemotherapy and radiotherapy for cancer or anti-retroviral drugs for HIV is not available. Prevention, although important, does not address the needs of the millions who already have the diseases.

In the general context of palliative care, Kellehear (Io) has discussed in detail the need for health-promoting palliative care and arranging alliances with public health colleagues. More specifically, the need for palliative care/pain control in developing countries is discussed prominently in the palliative care literature and to some extent in the mainstream literature and that of oncology and anesthetics (9,II-I8). However, a wide-ranging literature review (Medline, Embase, CINAHL) using the simple search strategy of combining the key words "palliative care" and "developing countries" failed to locate coverage of this issue in the public health literature. This suggests that the need for palliative care in developing countries is a public health issue, which public health practitioners and health policy makers may not be prioritizing. Greater advocacy for palliative care service provision by their colleagues in public health would potentially aid palliative care practitioners who are struggling to care for their patients in economically resource-poor countries.

As palliative care physicians and public health scientists, our position is that the scale of this epidemic of death and dying requires acknowledgement as a public health issue, with more than just an emphasis on prevention of these diseases and their cure. 


\section{What is Palliative Care?}

WHO currently defines palliative care as "an approach that improves the quality of life of patients and their families facing the problems associated with life-threatening illness, through the prevention and relief of suffering by means of early identification and impeccable assessment and treatment of pain and other problems, physical, psychosocial and spiritual" (I9). It is possible to more explicitly set out what constitutes good palliative care, but more important to recognize that effective palliative care needs to be appropriate to a particular country's culture, resources and existing health programs $(\mathrm{I} 5, \mathrm{I} 7, \mathrm{I} 8,20-23)$.

Furthermore, with almost half of the world's population living on less than US\$2 a day, and of that almost I.2 billion living on less than US\$ I a day (24), palliative care needs to be affordable and cost effective. A palliative care program needs to acknowledge poverty and the lack of the basic necessities of life both in developed countries where cost of medication is still a problem for some patients but especially in resource-poor developing countries (25-27).

\section{Distribution of Palliative Care Services}

It is estimated that there are hospice/palliative care services, either existing or under development, in about roo countries around the world with between 7,000 and 8,000 palliative care initiatives including community-based teams, inpatient units and day-care centers (28). The distribution of these services, however, is not even and is heavily weighted toward western countries. Only approximately 6 percent of all palliative care services are located in Asia and Africa, the regions where the majority of the world's population lives and dies.

The data on developing countries suggests that even in those countries where palliative care services exist, the coverage of many of the programs is limited and palliative care is not on the health agenda of their governments as a public health problem. This limits the ability of palliative care services to impact on the populations that most need them $(22,29-39)$.

In the majority of developing countries, little is known about the quality of care that people receive at the end of life. However, since 
the use of opioids is one of the most common methods used for pain control in palliative care, morphine consumption can be used as an approximate measure of the availability of pain control and hence availability of this form of palliative care $(5)$. Data are available on morphine consumption of each country per capita (40). Analysis of these data shows that the share of developing countries in the global consumption of morphine continues to be only around 6 percent, although these countries account for almost 80 percent of the world's population. In fact, in 2002 , only ro countries together accounted for 87 percent of the total world consumption of morphine (with similar figures for other opioid analgesics such as hydromorphone, fentanyl and oxycodone) (4I). These figures illustrate the discrepancies in pain control between developed countries and developing countries and, by extension, the availability of palliative care.

\section{WHY IS IT NOT HAPPENING?}

The knowledge already exists of how to improve the quality of life of those who are dying particularly in regards to pain relief, but it is not widely practiced $(42-44)$. As noted earlier, this is evident in developing countries and is partly attributable to the usual reasons for poor health care of any description including poverty and lack of basic necessities (food, clothes, clean water), lack of resources and inadequate health system infrastructure. There are, however, three specific barriers to palliative care implementation that are generally accepted as the major impediments: lack of government commitment, opioid availability and limited education $(\mathrm{I} 7, \mathrm{I} 8)$.

\section{Government Commitment}

As with any health initiative, the most important factor is government commitment. This includes commitment to palliative care generally, drug availability and education. Specific support for palliative care ideally should be in the context of general commitment to improving general health-care structures and access to health care for the country's population. WHO has recommended that each country has a national policy for implementing palliative care services which could be integrated into the existing health system and the country's cultural and social context (I7). Despite this, in 2002 
only one country in Africa, Uganda, had made palliative care for AIDS and cancer victims a priority in their national health plan, although South Africa has also included access to palliative care in its new health policies $(29,45)$.

Advocacy on behalf of palliative care provision would help raise awareness among government health departments of what palliative care can offer and how even simple changes in health policy can make a large difference in the quality of life of dying people. In particular, review and adjustment of opioid control policies would remove one of the major barriers to palliative medicine.

\section{Opioid Availability}

Although pain relief forms only a part of palliative care, it is a major part as very rarely can other symptoms be effectively treated or psychological anguish addressed if the patient is suffering uncontrolled pain. Despite ongoing advocacy from international bodies, opioids are still not readily available or available only under very strict conditions in many countries $(46,47)$. The difficulty with availability or distribution of opioids stems from legitimate concerns aimed at preventing the abuse or misuse of opioids although the literature states that providing morphine in sufficient quantities for legitimate use has not led to an increase in diversion or misuse of opioids $(4 \mathrm{I}, 48,49)$.

Many developing countries have fundamental barriers to obtaining or distributing drugs of any description (50), but when opioids are involved the barriers become even more of an issue, making them almost impossible to access $(20,34,35,38,48,5 \mathrm{I})$. One of the key barriers is manufacture and availability of morphine. Morphine is inexpensive to manufacture and should only cost about I cent US for Io mg of generic morphine sulfate tablets or morphine hydrochloride solution (I). This makes morphine the low cost, effective pain relief medication of choice in resource-poor countries. Research has shown that drug companies preferentially supply more expensive opioid formulations and drug types to developing countries rather than cheap, generic morphine (52). Hospice Africa, Uganda has demonstrated the feasibility of providing cheap oral morphine in resourcepoor settings. Oral morphine for Hospice patients (about 75 percent of all patients receiving oral morphine in Uganda up to 
now - Dr. Anne Merriman, personal communication) is made in the hospice pharmacy from morphine powder by the Pharmacy Dispenser who is authorized and monitored by the National Drug Authority. This formula has been made publicly available to demonstrate to other resource-poor countries how they could commence provision of oral morphine to their patients in a costeffective way (53).

With the knowledge that these barriers exist, WHO has produced guidelines for countries to follow to assess their opioid control policies and set appropriate systems in place (54). However, regulation and suggestion for change by international bodies is not always sufficient. Policy makers and health professionals need to understand why lifting unnecessary regulations is important and part of this includes education about the need for palliative care and correct use of opioids.

\section{Education}

There are many groups to target in order to maximize the impact of an educational program.

\section{Health professionals}

It is widely agreed that in order to establish a broad knowledge base of palliative care and widen coverage, integration of palliative care training into undergraduate training programs for nurses, doctors, pharmacists and other allied health professionals should be undertaken $(\mathrm{I} 8,43)$. Ongoing training programs for established health-care professionals such as oncologists, family doctors, geriatricians, HIV/ AIDS doctors and community nurses are also necessary (I7). Experience has shown this to be achievable not only in developed countries but also in developing counties $(33,55)$.

Local healers who have the trust of their community can, with provision of extra training and resources, combine traditional ways of managing certain illnesses with perhaps some new ways of providing symptom relief $\left(\mathrm{I}_{5}, 39\right)$.

A particular educational need that should be addressed for health professionals is fear of addiction or misuse of opioids and lack of basic education in the use of opioids which has led to "opiophobia", a chronic problem not only in developing countries 
but also in some developed countries, which usually leads to underprescription of pain relief medication $(26,32,34,35,38,42,56)$. Government sanction of the use of opioids would at least partially address the reluctance of many health-care professionals to prescribe opioids; however, education about use of opioids is still relevant.

\section{Family and volunteer caregivers}

A significant proportion of care in developing countries is provided by family members or volunteers particularly in rural areas where many patients will never see a doctor or nurse. Empowerment of these care-givers with training on personal care, psycho-social support and some medical care will aid in extending coverage of palliative care $(\mathrm{I})$.

\section{Public education}

It is not only the health professionals of a country who need to be educated but also the general public. Raising the profile of palliative care so that people know what options are available and are able to advocate for optimal care during a terminal illness will aid in convincing governments of the need to place it on the national health agenda.

\section{CAN IT HAPPEN?}

The large body of literature regarding the model service at Hospice Uganda has shown that overcoming the aforementioned barriers enables a resource-poor society to progress in palliative care service provision $(33,45,49,56-58)$. While Ugandan health services have numerous problems, the progress in palliative care provision in just Io years has been attributed to addressing the issues of government commitment, opioid availability and education (33).

The palliative care practitioners in Hospice Uganda, Africa, acknowledge that palliative care in Uganda is not perfect, nor is it yet close to reaching all the population $(33,57)$. Rapid growth needs consolidation in order to ensure that quality does not suffer; however, the progress in Uganda encourages other countries to believe that change is possible. 
Prevention and treatment of diseases are key public health strategies, but ethically we should not overlook the multitude of people who are already suffering while we plan for the future. Clinicians alone cannot take care of this issue as their hands are tied by lack of support from policy makers. Experience has shown that palliative care is possible even in resource-poor settings. It can be inexpensive and cost effective, and be integrated into established health-care systems. To have these skills and knowledge waiting to be used while literally millions die agonizing deaths is distressing for those who know that more could be done.

This article is not a comprehensive review of the topic. Rather, it seeks to provide sufficient information to raise awareness of the inequity that exists in current provision of palliative care between developed and developing countries. This is but one public health issue that deserves priority among many others and we would not argue that it is the most important. However, we would argue that it should not be neglected in the discussion of public health priorities.

\section{REFERENCES}

I. Stjernsward J, Clark D. Palliative medicine - a global perspective. In: Doyle D, Hanks G, Cherny N, Calman K, editors. Oxford Textbook of Palliative Medicine, 3 rd edition. New York: Oxford University Press Inc.; 2004, p. II99-224.

2. World Health Organization. World Health Report 2003. Geneva: World Health Organization; 2003. Available at http://www.who.int/ whr/2003/en/Annex2-en.pdf, accessed I 5 May 2004.

3. Parkin DM, Bray FI, Devesa SS. Cancer burden in the year 2000. The global picture. Eur J Cancer. 200I;37:S4-66.

4. 2006 Report on the Global AIDS Epidemic - Executive Summary. UNAIDS web site. Available at http://www.unaids.org, accessed $3 \mathrm{I}$ May 2006.

5. World Health Organization. Cancer Pain Relief and Palliative Care, Technical Report Series 804. Geneva: World Health Organization; 1990.

6. Breitbart W, Rosenfeld BD, Passik SD, McDonald MV, Thaler H, Portenoy RK. The undertreatment of pain in ambulatory AIDS patients. Pain. 1996;65(2-3):243-9.

7. Stephenson J. Experts say AIDS pain "Dramatically Undertreated". JAMA. 1996;276(17):1369-70. 
8. Morris K. Cancer? In Africa?. The Lancet Oncology. 2003; 4 (January): 5 .

9. Singer PA, Bowman KW. Quality care at the end of life. BMJ. 2002;324:I29I-2.

ıо. Kellehear A. Health-promoting palliative care: developing a social model for practice. Mortality. I 999;4(I):75-82.

I I. Aranda S. Global perspectives on palliative care. Cancer Nurs. I 999;22(I):33-9.

I2. Higginson IJ, Bruera E. Do we need palliative care audit in developing countries? Palliat Med. 2002; 6:546-7.

I3. Kumar A. Organization and development of pain clinics and palliative care in developing countries. Eur J Anaesthesiol. 2004;21:169-72.

I4. Martin WMC. Cancer in developing countries: Part II - cancer control: strategies and priorities. Clin Oncol. 1998;10:283-7.

I 5. Olweny CLM. Ethics of palliative care medicine: palliative care for the rich nations only!. J Palliat Care. I994;IO(3):17-22.

I6. O’Neill JF, Romaguera R, Parham D, Marconi K. Practicing palliative care in resource-poor settings. J Pain Symptom Manage. 2002; 24(2): I $48-5$ I.

I7. Sepulveda C, Marlin A, Yoshida T, Ullrich A. Palliative care: the World Health Organization's global perspective. J Pain Symptom Manage. 2002;24(2):9I-6.

I8. Stjernsward J. Instituting palliative care in developing countries - an urgently needed and achievable goal. J P Palliat Care Pharmacother. 2003; I7 (3/4):xxix-xvi.

19. WHO Definition of Palliative Care. World Health Organization web site. Available at http://www.who.int/cancer/palliative/definition/en/ print.html, accessed 28 January 2004.

20. Bruera E, Sweeney C. Palliative care models: international perspective. J Palliat Med. 2002;5(2):3 I9-27.

2I. Pampallona S, Bollini P. Palliative care in developing countries: why research is needed. J Pain Palliat Care Pharmacother. 2003;17(3/4): I 7 I -82 .

22. Rajagopal MR, Venkateswaran C. Palliative care in India: successes and limitations. J Pain Palliat Care Pharmacother. 2003; $17(3 / 4)$ : I 2 I-8.

23. Sureshkumar K, Rajagopal MR. Palliative care in Kerala: problems at presentation in 440 patients with advanced cancer in a south Indian state. Palliat Med. 1996;10:293-8.

24. International Bank for Reconstruction and Development/World Bank. World Development Report 2000/200I. New York, Oxford University Press; 2000. 
25. Alexander CS. Palliative Care for Disenfranchised Populations. Presented at the I4th International Congress on the Care of the Terminally Ill; October, 2002. Available at http://hab.hrsa.gov/ publications/palliative/front.htm, accessed 27 July 2004.

26. Gee RE, Fins JJ. Barriers to pain and symptom management, opioids, health policy, and drug benefits. J Pain Symptom Manage. 2003; 25(2): IOI-3.

27. Merriman A, Manjit K. Palliative care in Africa: an appraisal. The Lancet. 2005;365(June 4):1909-II.

28. Hospice Information website. Hospice and Palliative Care Facts and Figures 2005,2005 . Available at http://www.hospiceinformation.info, accessed 3I May 2006.

29. Beck SL. Health policy, health services, and cancer pain management in the New South Africa. J Pain Symptom Manage. I999;I7(I):I6-25.

30. Grant E, Murray SA, Grant A, Brown J. A good death in rural Kenya? Listening to Meru patients and their families talk about care needs at the end of life. J Palliat Care. 2003;19(3):159-67.

3I. Lai Y-L, Su WH. Palliative medicine and the hospice movement in Taiwan. Support in Cancer Care. I997;5:348-50.

32. Leong RLB. Palliative care in Malaysia: a decade of progress and going strong. J Pain Palliat Care Pharmacother. 2003;17(3/4):77-85.

33. Livingstone $\mathrm{H}$. Pain relief in the developing world: the experience of Hospice Africa - Uganda. J Pain Palliat Care Pharmacother. 2003; I7 $(3 / 4)$ : IO7-I 8.

34. Muirden N. Palliative care in Papua New Guinea: report of the international association of hospice and palliative care traveling fellowship. J Pain Palliat Care Pharmacother. 2003;I7(3/4):I9I-8.

35. Nervi F, Guerrero M, Reyes MM, et al. Symptom control and palliative care in Chile. J Pain Palliat Care Pharmacother. 2003;17(3/4):13-22.

36. Nixon A. Palliative care in Saudi Arabia: a brief history. J Pain Palliat Care Pharmacother. 2003; $17(3 / 4): 45-9$.

37. Sepulveda C, Habiyambere V, Amandua J, et al. Quality care at the end of life in Africa. BMJ. 2003;327:209-I3.

38. Spencer M. Pain relief in Thailand. J Pain Palliat Care Pharmacother. 2003; I7 (3/4):53-6I.

39. Harding R, Higginson IJ. Palliative care in sub-Saharan Africa. The Lancet. 2005;365(June 4):I97I-7.

40. World Health Organisation Collaborating Centre for Policy and Communications in Cancer Care. Availability of opioid analgesics in Africa and the World. Paper prepared for A Community Health Approach to Palliative Care for HIV/AIDS and Cancer Patients in Africa. Gaborone, Botswana; July 9-I2, 2002. 
4I. International Narcotics Control Board. Report of the International Narcotics Control Board for 2003. New York, NY: United Nations; 2003. Available at http://www.incb.org/e/ar/2003/menu.htm, accessed 27 July 2004.

42. Foley K. Pain relief into practice: rhetoric without reform. J Clin Oncol. I995;I3(9):2 I 49-5I.

43. Foley K. Dismantling the barriers: providing palliative and pain care. JAMA. 2000;283(I):I I 5 .

44. Jeffrey D. For whom the bell tolls - palliative care in the Third World. J R Soc Med. 1995;88:307-Io.

45. Stjernsward J. Uganda: initiating a Government Public Health approach to pain relief and palliative care. J Pain Symptom Manage. 2002;24(2):257-64.

46. International Narcotics Control Board. Report of the International Narcotics Control Board for 1995 Availability of Opiates for Medical Needs. New York, NY: United Nations; 1996. Available at http:// www.incb.org, accessed I7 July 2004.

47. Joranson DE, Colleau SM. Highlights of the INCB report. Cancer Pain Rel. I996;9(Suppl):I-4.

48. Rajagopal MR. Medical use, misuse, and diversion of opioids in India. Lancet. 200I;358(9276): 139-43.

49. Ramsay S. Leading the way in African home-based palliative care. Lancet. 2003;362:I 8I 2-3.

50. Cancer Pain Relief: a guide to opioid availability. In: Cancer Pain Relief, With a Guide to Opioid Availability, 2nd edition. Geneva: World Health Organization; 1996. Available at http://www. medsch.wisc.edu/painpolicy/publicat/cprguid.htm, accessed 27 July, 2004.

5I. De Lima L, Sakowski J, Stratton Hill C, Bruera E. Legislation analysis according to $\mathrm{WHO}$ and INCB criteria on opioid availability: a comparative study of 5 countries and the state of Texas. Health Policy. 200I;56(2):99-I 10.

52. De Lima L, Sweeney C, Palmer JL, Bruera E. Potent analgesics are more expensive for patients in developing countries: a comparative study. J Pain Palliat Care Pharmacother. 2003; 8 (I):59-70.

53. Merriman A. Pain and Symptom Control in the Cancer and/or AIDS patient in Uganda and Other African Countries, 4th edition. Kampala: Hospice Uganda, Africa; 2006.

54. Achieving Balance in National Opioids Control Policy: Guidelines for Assessment. Geneva: World Health Organization; 2000. Available at http://www.medsch.wisc.edu/painpolicy/publicat/oowhoabi/oowhoabi. htm, accessed 7 July 2004. 
55. Cairns W, Yates PM. Education and training in palliative care. Med J Aust. 2003;179(6 Suppl):S26-8.

56. Merriman A. Uganda: current status of palliative care. J Pain Symptom Manage. 2002;24(2):252-6.

57. Merriman A, Heller KS. Hospice Uganda - a model palliative care initiative in Africa: an interview with Anne Merriman. Innov Endof-Life Care. 2002;4(3).

58. Spence D, Merriman A, Binagwaho A. Palliative care in Africa and the Caribbean. PLoS Med. 2004; I(I):e5. 